\title{
Phase Formation in Contacting Zinc Melting with Indium and Stannic in the Presence of Strontium Impurity and Microhardness of Derived Alloys
}

\author{
Bagov A.M. \\ Management of Research and Innovation \\ Kabardino-Balkarian State University \\ Nalchik, Russian Federation \\ vegros@rambler.ru
}

Khasanov A.I.

Faculty of Physics and Information and Communication

Technologies

Chechen State University

Grozny, Russian Federation

Department of Materials

Kh. Ibragimov Complex Institute of the Russian Academy of Sciences

Grozny, Russian Federation

aslan2001@rambler.ru

Gachaev A.M.

Department of Physical and Mathematical Research

Kh. Ibragimov Complex Institute of the Russian Academy of Sciences

Grozny, Russian Federation

gachaev_chr@mail.ru

\begin{abstract}
Phase formation during contact melting, including in the presence of electric transfer, in the system indium-zinc and stannic-zinc with the introduction of a small admixture of strontium was studied. The formation of two-component intermetallic compounds has been established. An attempt has been made to explain the obtained results.
\end{abstract}

Keywords - contact melting, electrotransport, X-ray phase analysis, intermetallide

\section{INTRODUCTION}

It is known that various metallic admixtures can significantly change the properties of alloys and composite materials, and sometimes even lead to the formation of new substances. In this regard, it seems relevant to study the effect of small additives on the phase transition between two solid dissimilar materials, known as contact melting (CM). In addition, if impurities are chemically active, they will form new compounds. Considering all the above, we continued the study of metal CMs in the presence of alkaline-earth additives. In this work, zinc with a small admixture of strontium was used.

\author{
Tamaev T. Kh. \\ Management of Research and Innovation \\ Kabardino-Balkarian State University \\ Nalchik, Russian Federation \\ vegros@rambler.ru \\ Uspazhiev R.T. \\ Department of Physics \\ Grozny State Oil Institute \\ named after Acad. M.D. Millionshchikova \\ Grozny, Russian Federation \\ Department of Materials \\ Kh. Ibragimov Complex Institute of the Russian Academy \\ of Sciences \\ Grozny, Russian Federation \\ ruslan.80.87@mail.ru \\ Zubkhadzhiev M-A.V. \\ Faculty of Physics and Information and Communication \\ Technologies \\ Chechen State University \\ Grozny, Russian Federation \\ zmagamed-ali@mail.ru
}

\section{Methods AND MATERIALS}

$\mathrm{CM}$ of zinc solid solutions with indium and stannic was carried out in unsteady-diffusion mode in a thermostat filled with silicone oil PPHMS-2/5L [1]. Temperature experiments were $147^{\circ} \mathrm{C}$ and $202^{\circ} \mathrm{C}$. The experiments lasted 4 hours.

Also during the experiments, the effect of electromigration was studied $[2,3]$. For this, in one case, no electric current passed through the samples, and a constant electric current with a density of $0.5 \mathrm{~A} / \mathrm{mm} 2$ was passed through the other two. In this case, the direction of the current in them was the opposite. This condition is due to the fact that due to the difference in the effective charges [4] of different metals, depending on the polarity of the electromagnetic field, contact melting is accelerated or slowed down. The result is determined by the so-called "integral criterion of electric transfer" given in [1-5].

An X-ray phase analysis of the diffusion zones obtained was performed. The studies were carried out using a D2 Phaser X-ray diffractometer. The radiation wavelength was $1.54 \AA$, the width of the emitted beam was $0.8 \mathrm{~mm}$. Also, the microhardness of the contact zones was determined in the 
studied systems. The measurements were carried out on a PMT-3 microhardness meter according to the method described in [6].

\section{RESULTS}

\section{Zinc-indium system}

Tables 1 and 2 show the intermetallic compounds found in the diffusion zones during contact melting in the system $(\mathrm{Zn}+$ 0.5 at. $\% \mathrm{Sr})-\mathrm{In}$ and $(\mathrm{Zn}+0.74$ at.\% $\mathrm{Sr})-\mathrm{In}$, respectively, as well as the parameters of their crystal lattices.

TABLE I. INTERMETALLIDES AND PARAMETERS OF THEIR CRYSTAL LATTICES IN THE SYSTEM $(\mathrm{ZN}+0.50 \mathrm{AT} \% \mathrm{SR})-\mathrm{IN}$

\begin{tabular}{|c|c|c|c|c|}
\hline \multirow{2}{*}{ Intermetallide } & \multicolumn{3}{|c|}{ Conductance, $\mathbf{A} / \mathbf{m m}^{2}$} & \multirow{2}{*}{ Crystalline lattice } \\
\cline { 2 - 4 } & 0 & +0.5 & -0.5 & $\begin{array}{c}\text { Tetragonal } \\
(10.749 \AA \times 6.899 \AA)\end{array}$ \\
\hline $\mathrm{SrZn}_{11}$ & + & + & + & $\begin{array}{c}\text { Tetragonal }(8.738 \AA \times 16.442 \\
\AA\end{array}$ \\
\hline $\mathrm{Sr}_{5} \mathrm{In}_{3}$ & - & + & - & \\
\hline
\end{tabular}

TABLE II. INTERMETALLIDES AND PARAMETERS OF THEIR CRYSTAL LATTICES IN THE SYSTEM (ZN + 0.74 AT \% SR) -IN

\begin{tabular}{|c|c|c|c|c|}
\hline \multirow{2}{*}{ Intermetallide } & \multicolumn{3}{|c|}{ Conductance, $\mathbf{A} / \mathbf{m m}^{2}$} & \multirow{2}{*}{ Crystalline lattice } \\
\cline { 2 - 4 } & 0 & +0.5 & -0.5 & \\
\hline $\mathrm{SrZn}_{11}$ & + & + & - & $\begin{array}{c}\text { Tetragonal } \\
(10.749 \AA \times 6.899 \AA)\end{array}$ \\
\hline $\mathrm{SrZn}_{13}$ & - & - & + & Cubical $(12.242 \AA)$ \\
\hline
\end{tabular}

Note that in the system $(\mathrm{Zn}+0.5$ at.\% $\mathrm{Sr})-\mathrm{In}$ in all cases, the compound SrZn11 was formed, which, however, was absent in the Sr-Zn state diagram [7]. Apparently, it was already present in the solid solution of zinc with strontium and did not completely dissolve upon contact melting. With the accelerating direction of the current, there is also intermetallic compound $\mathrm{Sr}_{5} \mathrm{In}_{3}$. It is observed in the equilibrium melting diagram of the In-Sr system. The formation of this substance may be due to more intensive leaching of the $\mathrm{SrZn}_{11}$ compound to an area rich in indium. As a result, some $\mathrm{SrZn}_{11}$ could disintegrate, and strontium was captured by indium to form a new compound.

In the system $(\mathrm{Zn}+0.74$ at.\% $\mathrm{Sr})-$ In (table 2$)$, a slightly different picture is observed. Only strontium compounds with zinc are present. If in two versions of the experiment the compound $\mathrm{SrZn}_{11}$ was again detected, then the $\mathrm{SrZn}_{13}$ intermetallic was formed at the current slowing down direction. The second substance, in contrast to the first, is available on the $\mathrm{Sr}-\mathrm{Zn}$ state diagram [7].

Figure 1 shows the results of measuring the microhardness of the contact layer of the system $(\mathrm{Zn}+0.5$ at.\% $\mathrm{Sr})$ - In obtained in the absence of electric current.

Low values of the microhardness of the interlayer (within 40-60 MPa) compared with the microhardness of zinc (about $500 \mathrm{MPa}$ ) indicate an extremely low content of zinc in the resulting alloy. In this case, the zone adjoining the solid solution $(\mathrm{Zn}+0.5$ at.\% $\mathrm{Sr})$ is harder than the rest due to the smaller amount of indium in it. However, the further course of the microhardness is difficult to explain only by a decrease in the zinc content in the alloy, since at first this value drops rather sharply and then slightly increases. It can be assumed that in the compound zone the intermetallic compounds were unevenly distributed, which led to such non-monotonic microhardness behavior.

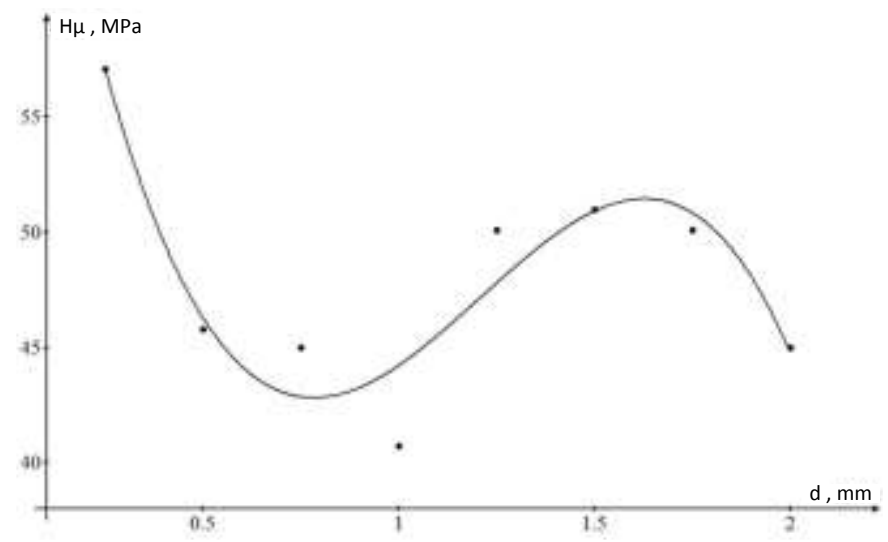

Fig. 1. Microhardness $(\mathrm{H} \mu)$ along the contact layer obtained at $\mathrm{CM}$ in the system $(\mathrm{Zn}+0.5$ at.\% $\mathrm{Sr})-\mathrm{In} ; \mathrm{d}$ is the distance from the measured point to the boundary with strontium solid solution in zinc

Figure 2 presents the results of measuring the microhardness of the contact layer of the system $(\mathrm{Zn}+0.74$ at.\% Sr) - In, obtained in the absence of electric current.

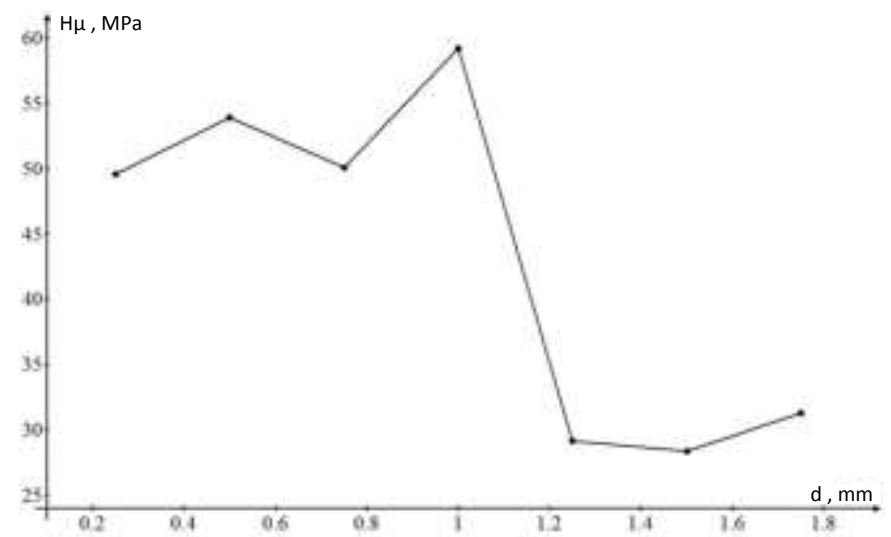

Fig. 2. Microhardness $(\mathrm{H} \mu)$ along the contact interlayer obtained at a $\mathrm{CM}$ in the system $(\mathrm{Zn}+0.74$ at. $\% \mathrm{Sr})-\mathrm{In}$; $d$ is the distance from the measured poin to the boundary with the solid solution of strontium in zinc.

The microhardness of the alloy along the interlayer in this experiment is not explained by the usual arguments about the distribution of components along the zone. In the region lying near the solid solution $(\mathrm{Zn}+0.74$ at.\% $\mathrm{Sr})$, the microhardness lies within 50-60 MPa, and it does not decrease with the distance from the boundary. This is followed by a sharp decrease to about $30 \mathrm{MPa}$, and also does not decrease when approaching the indium sample. There is only an assumption that for some reason intermetallic compounds do not penetrate into the second half of the diffusion zone, creating a barrier for zinc too.

Zinc - stannic system 
Tables 3 and 4 show the intermetallic compounds found in the diffusion zones during contact melting in the system $(\mathrm{Zn}+$ 0.5 at.\% $\mathrm{Sr})-\mathrm{Sn}$ and $(\mathrm{Zn}+0.74$ at.\% $\mathrm{Sr})-\mathrm{Sn}$, respectively, as well as the parameters of their crystal lattices.

TABLE III. INTERMETALLIDES AND PARAMETERS OF THEIR CRYSTALLINE LATTICES IN THE SYSTEM $(\mathrm{ZN}+0.5$ AT. $\%$ SR $)-\mathrm{SN}$

\begin{tabular}{|c|c|c|c|c|}
\hline \multirow{2}{*}{ Intermetallide } & \multicolumn{3}{|c|}{ Conductance, $\mathbf{A} / \mathbf{m m}^{2}$} & \multirow{2}{*}{ Crystalline lattice } \\
\cline { 2 - 4 } & 0 & +0.5 & -0.5 & \\
\hline $\mathrm{SrZn}_{11}$ & - & + & + & $\begin{array}{c}\text { Tetragonal } \\
(10.749 \AA \times 6.899 \AA)\end{array}$ \\
\hline $\mathrm{SrZn}_{13}$ & + & - & - & Cubical $(12.242 \AA)$ \\
\hline $\mathrm{SrSn}_{5}$ & - & - & + & $\begin{array}{c}\text { Monoclinal }(12.175 \AA \times 4.062 \\
\AA \times 5.163 \AA)\end{array}$ \\
\hline
\end{tabular}

TABLE IV. INTERMETALLIDES AND PARAMETERS OF THEIR CRYSTALLINE LATTICES IN THE SYSTEM $(\mathrm{ZN}+0.5$ AT. $\%$ SR $)-\mathrm{SN}$

\begin{tabular}{|c|c|c|c|c|}
\hline \multirow{2}{*}{ Intermetallide } & \multicolumn{3}{|c|}{ Conductance, $\mathbf{A} / \mathrm{mm}^{2}$} & \multirow{2}{*}{ Crystalline lattice } \\
\hline & 0 & +0.5 & -0.5 & \\
\hline $\mathrm{SrZn}_{11}$ & + & + & - & $\begin{array}{c}\text { Tetragonal } \\
(10.749 \AA \text { x } 6.899 \AA)\end{array}$ \\
\hline $\mathrm{SrZn}_{5}$ & - & - & + & Hexagonal $(12.002 \AA$ x $32.94 \AA)$ \\
\hline $\mathrm{SrSn}_{3}$ & - & - & + & $\begin{array}{c}\text { Monoclinal }(12.175 \AA \text { x } 4.062 \AA \\
\text { x } 5.163 \AA)\end{array}$ \\
\hline
\end{tabular}

In the system $(\mathrm{Zn}+0.5$ at. $\% \mathrm{Sr})-\mathrm{Sn}$, by passing an electric current, a SrZn11 compound is formed, which is absent in the $\mathrm{Sr}-\mathrm{Zn}$ state diagram [7]. In the currentless variant of the experiment, the intermetallic compound $\mathrm{SrZn}_{13}$ is found instead. There is a logical assumption that, in the presence of current, $\mathrm{SrZn}_{13}$ decomposes with the formation of $\mathrm{SrZn}_{11}$ and the release of free zinc. Check this in our experiments is not possible. At the same time, when the current is slowing down, the $\mathrm{SrSn}_{5}$ compound also appears.

In the system $(\mathrm{Zn}+0.74$ at. $\% \mathrm{Sr})-\mathrm{Sn}$, the $\mathrm{SrZn}_{11}$ intermetallic compound is present in the absence of current and its accelerating direction. In these, it is the only compound in the contact zone. When the current is slowing, it disappears. In this case, two other intermetallic compounds are formed $\mathrm{SrSn}_{3}$ and $\mathrm{SrZn}_{5}$, which are present on the $\mathrm{Sr}-\mathrm{Sn}$ and $\mathrm{Sr}-\mathrm{Zn}$ state diagrams [7]. Since both of these compounds are richer in strontium than $\mathrm{SrZn}_{11}$, it can be assumed that an inversion of the effective charges of the components occurred, which led to a greater diffusion of strontium-containing substances towards tin and their decomposition in this area with the formation of new compounds. This assumption is also supported by the fact that in the system $(\mathrm{Zn}+0.5$ at.\% $\mathrm{Sr})-$ $\mathrm{Sn}$, the $\mathrm{SrSn}_{5}$ intermetallic compound was also synthesized under the moderating current.

Figure 3 presents the results of measuring the microhardness of the contact zone of the system $(\mathrm{Zn}+0.5$ at. $\% \mathrm{Sr}$ ) -Sn obtained in the absence of electric current.

Despite the relatively small variation in the values (maximum $40 \mathrm{MPa}$ ), the microhardness along this layer behaves rather unusual. The softest areas are near the boundaries, and if this is understandable in the case of stannic, the low values near the boundary with the solid solution of strontium in zinc are surprising. In the middle part, the microhardness generally gradually decreases with distance from $(\mathrm{Zn}+0.5$ at.\% Sr), although there are also deviations here. This observation can be explained only by the concentration of zinc (for some reason) in the middle part of the layer.

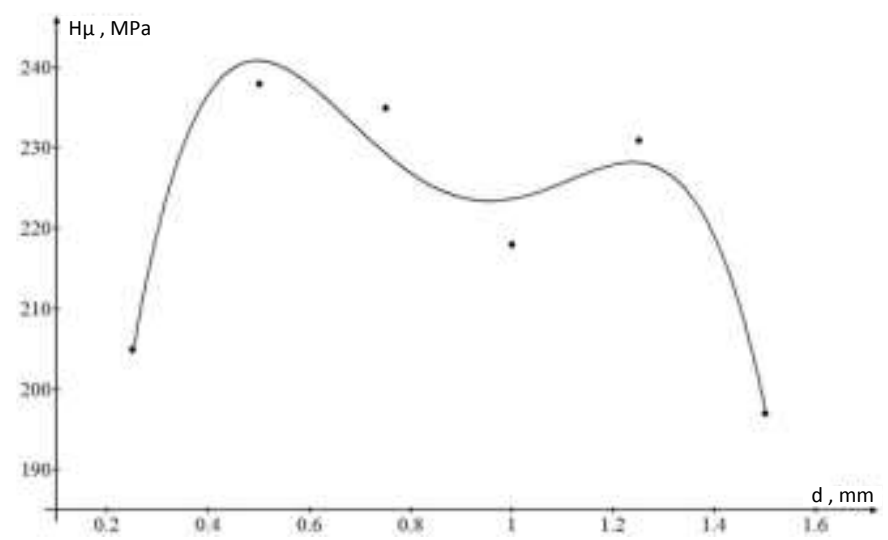

Fig. 3. Microhardness $(\mathrm{H} \mu)$ along the contact interlayer obtained at a $\mathrm{CM}$ in the system $(\mathrm{Zn}+0.5$ at.\% $\mathrm{Sr})-\mathrm{Sn}$; $\mathrm{d}$ is the distance from the measured point to the boundary with the solid solution of strontium in zinc.

Figure 4 presents the results of measuring the microhardness of the contact zone of the system $(\mathrm{Zn}+0.74$ at.\% Sr) $-\mathrm{Sn}$, obtained in the absence of electric current.

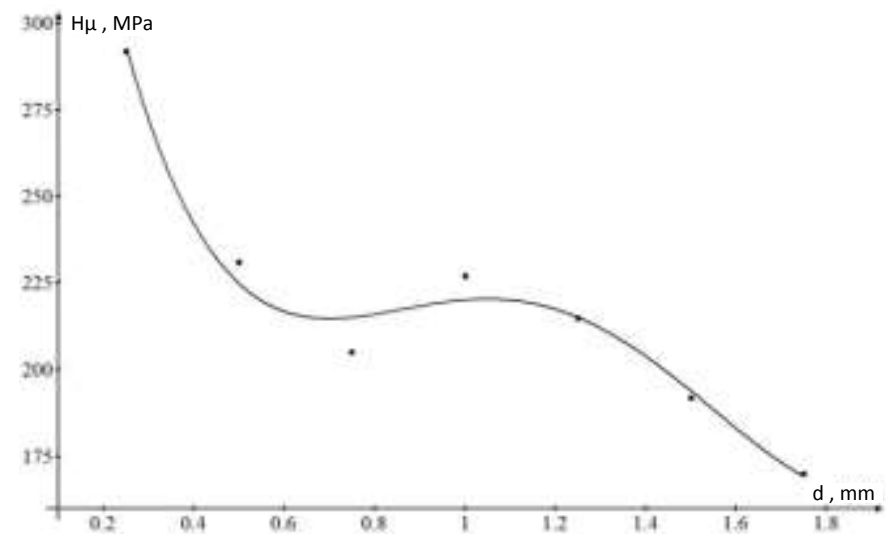

Fig. 4. Microhardness $(\mathrm{H} \mu)$ along the contact layer obtained by the $\mathrm{CM}$ in the system $(\mathrm{Zn}+0.74$ at.\% $\mathrm{Sr})-\mathrm{Sn} ; \mathrm{d}$ is the distance from the measured point to the boundary with the solid solution of strontium in zinc.

The microhardness of this alloy with a distance from the boundary with a solid solution of strontium in zinc monotonously decreases, except for the region in the middle of the diffusion zone $[8,9]$. Apparently, in the currentless mode, the distribution of components in the interlayer, despite the presence of an intermetallic compound, is close to that dictated by their state diagram [10]. In comparison with the system ( $\mathrm{Zn}$ +0.5 at. $\% \mathrm{Sr}$ ) $-\mathrm{Sn}$, the region near the solid solution is harder, and the region near stannic is softer.

\section{CONCLUSION}

Studies have shown that contact melting of indium and stannic with a solid solution of strontium in zinc produces intermetallic compounds, some of which are absent in 
equilibrium state diagrams. Electric current can influence their formation, and its direction is also important. A small difference in the content of strontium in the initial solution nevertheless has a noticeable effect on the resulting alloy. This can be seen in the flow of microhardness along the interlayers, which undergoes considerable leaps, and in different directions.

\section{Acknowledgment}

The study was carried out with the financial support of the Russian Foundation for Basic Research in the framework of research project No. 16-32-00666 mol_a.

\section{References}

[1] A. A. Akhkubekov, T. A. Orkvasov, V. A. Sozaev, Contact melting of metals and nanostructures based on them, 2008, p. 152.

[2] A.M. Bagov, Effect of electric transfer on mutual diffusion and macroscopic flow of the melt formed during contact melting, doctoral thesis, 2016, p. 156
[3] A. A. Kutsenko, Investigation of the influence of electric current on the structure formation and properties of high-quality castings, doctoral thesis, 2014, p. 158.

[4] A. A. Akhkubekov, S. N. Akhkubekova, A. M. Bagov, M. F. Bagova, T. Kh. Tamaev, "Connection of effective charges with electronegativity of atoms", Proceedings of the Russian Academy of Sciences. Physical series, vol. 81, no. 5, 2017, pp. 699-702.

[5] A. A. Akhkubekov, B. S. Karamurzov, "Relationship between diffusion and electrical transfer parameters of binary melts during contact melting", Letters Journal of Technical Physics, vol. 28, 2002, pp.60-65.

[6] V. Z. Afashokov, The influence of electromagnetic fields on the phase composition and structure of liquid-solid alloys with different conductivity of solid inclusions, doctoral thesis, 2011, p. 135.

[7] N. P. Lyakishev, State diagrams of double metal systems: a reference book in 3 volumes, 1996-2001.

[8] B.S. Bokstein, Diffusion in metals. Moscow:Metallurgy, 1978, p. 270

[9] D.K. Belashchenko, Transport phenomena in liquid metals and semiconductors. Moscow:Atomizdat, 1970, p. 399

[10] V.S. Savvin, Phase transitions of the first kind in contact of dissimilar metals, doctoral thesis, 2009, p. 310. 